\title{
La historia tal como mi abuela me contó. La memoria personal frente a la memoria colectiva sionista
}

\author{
Sigal Nagar-Ron
}

Me acompaña un recuerdo de la niñez: mi madre y mi abuela hablando. Mi abuela habla árabe en dialecto judeo-iraquí y mi madre le responde en hebreo. Yo, una niña pequeña, presto atención a su conversación y trato de entender, descifrar, descubrir el significado. Puedo entender sólo lo dicho en hebreo por mi madre. Sólo la mitad del diálogo se presenta al descubierto para un israelí; la otra parte del diálogo, la que está en árabe, queda oculta y debo completar las lagunas de información por medio de la lógica y la imaginación.

Este recuerdo infantil concreto funge como metáfora de la vivencia de israelíes judíos que sin tener un pasado común tienen memoria colectiva. Estos israelíes son hijos y nietos de judíos llegados a Israel en 1948, con la fundación del estado de Israel, provenientes de países árabes musulmanes, especialmente en los años cincuenta. La memoria de los judíos venidos de países árabes casi siempre está atada a los patrones de ese discurso hegemónico que es el del sionismo.

En el presente artículo quisiera plantear un testimonio histórico alternativo, personal, que permita desafiar los clichés institucionales. La experiencia personal no es un medio que representa a una población amplia, sino que provee un punto de acceso para la comprensión de procesos sociales complejos. ${ }^{1}$

Quisiera aludir al relato personal de mi abuela, que nació y creció en Bagdad, Irak, y llegó a Israel en 1950, casada y con tres hijas, a fin de identificar contradicciones ideológicas en la narrativa israelí-sionista hegemónica y la memoria histórica colectiva que la constituye.

${ }^{1}$ Acerca del papel de las historias personales en general y de la conciencia subyugada en particular por oposición a la violencia epistemológica que les ha sido impuesta, véase Hardings 1998; Stivers 1993; Smith 1993; Wisweswaran 1994 , etc. 
I call to mind a childhood memory: My mother and my grandmother are talking. My grandmother is speaking Arabic in a Jewish-Iraqi dialect and my mother is answering her in Hebrew. I, as a small child, am listening to them and trying to understand, to interpret, to reveal the meaning. I can only understand what is spoken in Hebrew, by my mother. Only half of the dialogue is open to me - the Israeli (the Hebrew), the other half of the dialogue - the Arabic, remains implicit and I must fill in the gaps, using the powers of imagination and logic.

This concrete childhood memory serves as a metaphor for describing the life experience of many Israelis-Jews who have no past, only a collective memory. These Israelis are the sons and grandsons of Jews who came to Israel from Arabic and Islamic countries upon the establishment of the State of Israel in 1948 and mainly during the 1950s. The memory of Jews from the Arabic countries is almost always bound to the hegemonic discourse structures, the Zionistic discourse. In this article I would like to propose an alternative, personal historical testimony that will enable challenging the institutional structures. The personal experience is not a means of representing a broad population; rather it offers an entry point for understanding complex social processes. ${ }^{2}$

I wish to use my grandmother's personal story - who was born and raised in Baghdad in Iraq and who came to Israel in 1950, a married woman with three daughters - in order to point out ideological contradictions in the hegemonic Israeli-Zionist narrative and the collective historical memory that was established.

${ }^{2}$ On the role of personal stories in general and subjugated knowledge in particular in objection to the epistemological violence that they were sentenced to, see, for example: Harding 1998; Stevers 1993; Smith 1993; Visweswaran 1994, and others. 
Sigal Nagar-Ron

Universidad Ben Gurion de Beer Sheva, Israel

\section{La historia tal como mi abuela me contó. La memoria personal frente a la memoria colectiva sionista}

Traducción del hebreo de Silvana Rabinovich

\section{Fundamento teórico}

Los primeros inmigrantes judíos que llegaron a Palestina/Israel, a fines del siglo XIX y comienzos del xx, eran europeos; pertenecían al movimiento sionista, cuyo objetivo era resolver el problema de los judíos en Europa mediante la fundación de un Estado judío en los territorios de Palestina. Al final de la segunda guerra mundial, cuando se supieron las proporciones de la desgracia del pueblo judío, y el movimiento sionista entendió que los recursos humanos para quienes se había fundado la nueva sociedad fueron exterminados en su mayoría durante el Holocausto, dicho movimiento orientó sus esfuerzos hacia los judíos que vivían en los países árabes y musulmanes.

Los esfuerzos del movimiento sionista junto con el nacionalismo árabe, que había comenzado a ascender en los años cuarenta del siglo $\mathrm{xx}$, condujeron a un vaciamiento casi total de las comunidades judías en países árabes durante los años cincuenta del siglo pasado. Los judíos que habían vivido durante 
siglos en sociedades árabes y musulmanas emigraron al nuevo Estado, Israel.

La memoria colectiva israelí es una memoria diseñada por el movimiento sionista y está basada en la historia de los judíos de Europa. Según la historia sionista imaginada, la historia de los judíos es la del exilio: durante dos milenios los judíos sufrieron el antisemitismo y las persecuciones en todos los países en los cuales vivieron y su única posible redención estaría dada por la fundación de un Estado-nación judío. Según la narrativa sionista, gracias a idealistas y pioneros sionistas, fundadores del Estado en Palestina/Israel, el movimiento sionista logró salvar de un destino cruel a los judíos que quedaron en Europa y en los países árabes.

Mediante procesos de socialización para los inmigrantes y para la joven generación que nació en Israel, para quienes la historia de la vida en el exilio no formó parte de su biografía, el relato histórico sionista fue legado como la narrativa hegemónica. En los libros de historia utilizados en el sistema de educación israelí casi no se toma en cuenta la historia de los judíos en los países árabes, ${ }^{3}$ y cuando se alude a esta historia es en beneficio de la narrativa sionista. ${ }^{4}$ Como consecuencia de esto, la joven generación no conoce la historia de su grupo étnico sino solamente la historia hegemónica oficial. La interiorización del ethos sionista realizada por los descendientes de los inmigrantes que provenían de países árabes, no sólo les

${ }^{3}$ El artista oriental Meir Gal encontró que en los libros de historia estudiados en los colegios sólo nueve páginas de las 400 que hay en total son dedicadas a la historia de los judíos en países árabes. "La historia israelí" es la historia de los judíos europeos (Gal 1997).

${ }^{4}$ La historiografía de las comunidades judías en los países árabes que se estudia en los programas escolares está basada solamente en los capítulos de la historia sionista (organizaciones sionistas en las comunidades orientales, activistas del sionismo de origen oriental y relatos de inmigración ilegal a Israel previos a la fundación del Estado), a pesar de la marginalidad del sionismo en la vida de esos judíos. Además, muchas comunidades judías en países árabes se oponían a las organizaciones sionistas (Shohat 1988). 
arrebata su pasado sino que a la vez se ve envuelta en los estereotipos acerca de Oriente y los orientales: a pesar de que la mitad de la población llegó de los países árabes islámicos, definidos como países orientales, ${ }^{5}$ el Estado de Israel se ve a sí mismo y se presenta ante el mundo como un Estado occidental. En tanto Estado que se ve a sí mismo como una sociedad occidental moderna, se produce en Israel una tensión inmanente entre Oriente y Occidente. La base de la conciencia y el pensamiento israelí se funda en premisas orientalistas. Según Said, ${ }^{6}$ el orientalismo es un discurso occidental que construyó una imagen de Oriente como primitivo, retrasado, retrógrado, violento, emocional, pasivo, sucio y exótico. Y por la oposición de lo europeo a lo oriental, Occidente se creó una identidad ilustrada y de progreso. Lo "occidental” es la antítesis absoluta de lo "oriental": avanzado, ilustrado, racional, productivo, lindo y limpio. En Israel la tensión Oriente-Occidente se fortaleció a partir del conflicto prolongado entre la nacionalidad judía y la nacionalidad árabe-palestina.

Ella Shohat (1988) fue la primera que reparó en la importancia de la perspectiva orientalista para la comprensión de la conciencia y la sociedad israelí. Shohat sostiene que el sionismo es un caso particular de eurocentrismo: la consecuencia directa de la negación del Oriente por parte del sionismo se manifiesta en la negación de los judíos que inmigraron desde países orientales. La concepción más expandida entre el público israelí sostiene que por haber vivido durante siglos en países árabes, los judíos se contagiaron de los males que padece la cultura oriental: atraso, pobreza, primitivismo, pasividad y fatalismo. Por esta razón se ve a los judíos orientales ${ }^{7}$ que llegaron

\footnotetext{
${ }^{5}$ En los medios nacionales e internacionales, Israel se presenta como "la única democracia del Medio Oriente", esto es, como un Estado occidental moderno e ilustrado, como una isla de progreso en un mar levantino.

${ }^{6}$ Said 1978.

${ }^{7}$ La denominación precisa debería ser "judíos árabes”. El discurso sionista (eurocéntrico, salvo desoídas excepciones como la de Martin Buber y el movimiento
} 
a Israel como salvados por el movimiento sionista de una vida de degeneración moral en los países árabes. ${ }^{8}$

La academia israelí interiorizó estas representaciones y las investigaciones que produjo las reforzaron. Pnina Motzafi-Haller, ${ }^{9}$ investigadora sobre el tema de mujeres orientales, encontró que las investigaciones que tuvieron lugar desde la gran inmigración de los judíos árabes a Israel a principios de los años cincuenta y hasta mediados de los setenta del siglo pasado estuvieron muy influenciadas por la concepción orientalista paternalista generalizada. Las mujeres judías árabes fueron presentadas como analfabetas, ignorantes, necesitadas de asistencia social, pasivas, dominadas por maridos violentos, madres de numerosos hijos, incapaces de criarlos adecuadamente, atrasadas, que padecen problemas psicológicos por el cambio hacia una sociedad moderna. Por medio de estos "descubrimientos científicos" la academia israelí creó a la

\footnotetext{
"Brit shalom"), al oponer lo árabe (lengua, etnia) a lo judío, rechazó este binomio por considerarlo un oxímoron. "Árabe" se redujo al significado de "enemigo". En sus orígenes, el Estado de Israel se pretendió como un "crisol de culturas", donde las diferencias y las singularidades serían sacrificadas en aras de una "nueva" cultura (que este artículo desenmascara como la hegemonía de la tradición europeizante pretendiendo borrar el componente árabe oriental). Así surge en hebreo el eufemismo "judío oriental” (yehudí mizrají) para definir aún hoy a esta numerosa población de ascendencia árabe y judía a la vez (sin considerar que el lugar donde se desarrolla este discurso hebreo está en el Oriente Medio y que quienes nacieron en esa región del Levante son mesoorientales). La nación árabe incluye tanto a musulmanes, como a cristianos y judíos. Sería más preciso geográficamente decir que todos los israelíes son orientales, y que los judíos inmigrados nacidos en países árabes son árabes, tanto como los judíos europeos son europeos. En el presente trabajo sólo respetaremos la expresión "judío oriental" cuando es pronunciada por la entrevistada, por respeto a la literalidad del discurso; por la misma razón prevalecerá el uso coloquial de la lengua. En el resto del artículo traduciremos "judío árabe" y cuando no sea así la expresión figurará entre paréntesis (N. de la T., previo acuerdo con la autora).

${ }^{8}$ Tzvi Ben Dor, en su conocido artículo "La maravillosa historia de los orientales" (Ben Dor 1999), muestra la forma en que el ethos de la liberación de los orientales fue estereotipado por manos del movimiento sionista al principio y más tarde por el partido político de derecha (Likud).

${ }^{9}$ Motzafi-Haller 2005.
} 
mujer judía árabe como un otro absoluto. ${ }^{10}$ Frente a la imagen de la "mujer oriental" se erige la imagen del "israelí sionista": hombre, de ascendencia europea, culto, liberal, ilustrado, activo y productivo.

Me interesa trabajar sobre un testimonio oral de una historia de vida que desafía a la historia oficial. El cuestionamiento de la narrativa hegemónica tiene lugar a partir una "historia de abajo", desde una historia de las voces marginales. Mi objetivo es ofrecer una comprensión alternativa de la sociedad, crear otras perspectivas de la historia colectiva y examinar nuevamente los conceptos hegemónicos.

\section{La historia de Salima}

Mi abuela materna nació en 1928 en Bagdad, Irak. Se puso feliz cuando le pedí que me contara su historia. Se entusiasma al contar su pasado que hasta hoy nadie había indagado. Lo cuenta en la lengua que aprendió en Israel, el hebreo, pero cuando reconstruye acontecimientos dramáticos, vuelve a contarlos en la lengua original en la que acontecieron: en árabe. $\mathrm{Al}$ cabo de tres horas en las que expone su historia cronológicamente, agrega que tiene mucho más para contar, y si lo deseo está dispuesta a narrarme más de sus experiencias la próxima vez. Al final de la entrevista le pregunto con qué nombre quiere que la presente, ya que su nombre original es árabe, Salima, pero cuando llegó a Israel le exigieron cambiar su nombre al de "Shulamit", que es un nombre judío bíblico. Sin dudarlo me responde "Salima, mi nombre es Salima". Me estremeció su elección tan decidida, ya que se trata de un nombre por el que hace 56 años ya nadie la llama.

${ }^{10}$ Said explica que por medio de una ciencia aparentemente neutral y sus análisis psicológicos, así como mediante las descripciones sociológicas propias del discurso hegemónico, el poder hegemónico oprime a quien determina como su "otro". 
Salima cumple con todos los criterios de "la mujer oriental". Es analfabeta, desde joven se vio obligada a dejar la casa pobre de sus padres para ir a vivir con su tío, un hombre de posición acomodada. Narra que

a los 10, 11 años no me llevaba bien con sus hijas, entonces regresé con mis padres. Luego me encontraron un trabajo. Trabajé como empleada doméstica día y noche. Para todo el mes me daban un dinar. Pero sabes qué: duermo en su casa, como, sólo los sábados voy a casa de mi familia por unas horas y regreso.

Durante varios años trabajó como empleada doméstica, hasta que a los 14 años se casó con su primo.

La conciencia israelí orientalista construyó la imagen de "la mujer oriental" uniendo datos objetivos correspondientes a una mujer que creció en un país árabe (falta de educación formal, pobreza y matrimonio antes de los 20 años) con características tales como estupidez, pasividad, dependencia, infantilidad y fatalismo. Esta representación de "la mujer oriental" posibilitó su explotación y marginalización cultural (y también económica) de la sociedad israelí.

En la sociedad israelí Salima la analfabeta es "la mujer oriental" estereotípica, y desde el día de su llegada a Israel, todos se relacionaron con ella a partir de este estigma: desde los representantes de instituciones gubernamentales (maestros, trabajadores sociales, médicos, etc.) hasta sus hijos. Su historia de vida, que nunca fue contada, nos permite abordar la historia desde una perspectiva que no tuvo lugar en la historiografía sionista. El desnudamiento de una historia alternativa nos permite mostrar algunas fisuras en las "verdades" que se encuentran en los cimientos del estereotipo de "la mujer oriental" que condujo a estas mujeres a los márgenes económicos, culturales y geográficos en Israel. 
Salima elige comenzar su historia de vida el día en que ocurrió el Farhud. ${ }^{11}$ El Farhud tuvo lugar el $1^{\circ}$ y el 2 de junio de 1941 (tuvo una duración aproximada de 30 horas), es un acontecimiento traumático para la historia de los judíos de Irak, que tuvo lugar por un vacío en el poder: ocurrió unas pocas horas antes de la entrada de los británicos en Bagdad durante la segunda guerra mundial. El primer ministro, pronazi, Rashid Alí al-Kaylani huyó, mientras el ejército británico y el heredero de la corona iraquí demoraron en tomar el mando de la ciudad. ${ }^{12}$ Como consecuencia de la anarquía en el gobierno, en las calles de Bagdad unos alborotadores cometieron desmanes, la mayoría de ellos eran beduinos que asaltaron, violaron y asesinaron a judíos. ${ }^{13}$ No hay un número exacto de víctimas de las violencias y se estima que fueron asesinados entre 150 y 200 judíos. Los investigadores coinciden en que se trata de un acontecimiento excepcional en las relaciones entre judíos y musulmanes en Irak, sin embargo en la narrativa sionista el Farhud se cuenta como parte de los acontecimientos de la Shoá, y sirve para demostrar que los judíos de Irak padecieron pogromos como en Europa. ${ }^{14}$

A pesar de que Salima escoge iniciar su relato con este acontecimiento, que en la historiografía sionista sirve como parteaguas en la historia de los judíos de Irak, en su narración

${ }^{11}$ En el léxico sionista el Farhud se define como pogromo. A fin de no utilizar la terminología sionista, presentaré el acontecimiento por su nombre original, en árabe: Farhud.

${ }^{12}$ Irak fue fundado como Estado en 1921 bajo un régimen de monarquía democrática. La Sociedad de Naciones dejó en manos de Gran Bretaña todo lo que se hiciera en el flamante Estado. Por razones internas y externas, el gobierno de Irak no era estable y entre 1921 y 1958 cambió 59 gobiernos parte de ellos consecuencia de revueltas militares (Yapp 1996). Rashid Alí al-Kaylani fue primer ministro y asumió el gobierno en un golpe militar que había sido subvencionado por los alemanes. Cuando se acercaba el ejército británico, el primer ministro huyó de Bagdad. El vacío de poder (que dio lugar el Farhud) se produjo en el ínterin, desde su huida hasta la llegada de los británicos y del rey.

${ }^{13}$ Somekh 2004, 104.

${ }^{14}$ Shenhav 2003, 154. 
hay testimonios que horadan el relato sionista. Pnina MotzafiHaller ${ }^{15}$ constató que mujeres judías árabes de clase baja tienden a adoptar como marco de sus historias personales los elementos centrales del relato nacional sionista. También la historia de Salima es prisionera de la narrativa nacional sionista en cuyos márgenes ella fue insertada; sin embargo una lectura más cercana de su narrativa personal da cuenta de brechas entre el relato personal y el relato hegemónico. La historia de vida propone lugares de contraposición, de diálogo y de redefinición del relato nacional masculino. Por eso no puede ser leída como un complemento o como un recorte de la narrativa nacional. Ella relata:

Me comprometí a los 12 años. Allá, en Irak, poquito a poco se le va comprando a la hija una dote. Durante todo un año mi madre me fue comprando ropa, cortinas, sábanas. Vino el Farhud. Vinieron a robar. Yo estaba en la casa donde trabajaba, en la colonia de los judíos ricos. Entonces escuché en el barrio... y nosotros éramos vecinos de los árabes en el barrio llamado "la calle cafecito". Allá todos son pobres, ellos (los árabes) son pobres, y nosotros (los judíos) somos pobres. Ellos tienen sus casas y nosotros vivíamos allá, una casa judía, una casa árabe. Vivíamos bien. No estaba mal. Hasta que en tiempos de Hitler se les calentó la cabeza. En tiempos de Hitler solíamos escuchar en las calles "ktilo al yahod, ktilo al hayod" ("maten a los judíos, maten a los judíos", en árabe). [...] Los árabes se llevaban a las chicas embarazadas, les cortaban el vientre, les sacaban los bebés. Día y noche hicieron una carnicería. Entonces yo dije, por lo visto mis padres se fueron (murieron), y mi hermana... entonces me vestí con la abaya. ${ }^{16}$ Nos poníamos la abaya para cubrir la cabeza. Entonces fui a casa de mis padres, no vi a nadie en casa. Encontré a mi hermana menor. Fuimos juntas a buscar a nuestros padres. Entrábamos a las

\footnotetext{
${ }^{15}$ Motzafi-Haller 2005.

${ }^{16}$ Abaya: traje femenino árabe tradicional, vestido largo, con mangas largas y cabeza cubierta.
} 
casas como si fuésemos árabes, vestíamos ropas árabes, cubrimos nuestros rostros, íbamos descalzas, queríamos ver. Entonces, fui, vi... ¡qué espanto! Vi a las mujeres embarazadas, siete niños degollados uno encima del otro. A un muchacho le habían cortado el miembro y se lo introdujeron en la boca. Niños en todas las casas, los quemaron. Hicieron algo... Y hay árabes que son verdaderamente buenos, que vivían con nosotros, nos agarraron, es decir, nos defendieron. Nos llevaron a su casa. Pero, sabes, nuestra casa se nos fue. Todo se llevaron los beduinos. Mi dote. Todo [...] Entonces entró Jordania y nos salvó de todo. Después entraron los ingleses y todo estaba bien. Luego vino el rey de Jordania, los ingleses entraron, y la casa se puso en orden. Nos dieron algo de dinero, la vida volvió. Pero sabes que después (del Farhud) había trabajo. Los judíos trabajaban para los ingleses. Se volvió América. Después de uno o dos años Inglaterra salió, Jordania se fue a su lugar, vino el reemplazante del rey. ${ }^{17}$ Una vez nos pegan, otra vez vivimos con ellos. Una vez así y otra vez asá, nos las arreglábamos. Ellos (los árabes) estaban bien. A veces en sábado, como nosotros no encendemos fuego, ellos venían y (nos) encendían el gas (la estufa). En las fiestas nos traían un regalo. Nosotros también les llevábamos regalos en sus fiestas. Los invitábamos a nuestras bodas, y ellos nos invitaban a las de ellos. Vivíamos juntos para bien y para mal.

A pesar de que Salima escoge iniciar su historia de vida con el duro acontecimiento de los escándalos del Farhud, que la historiografía sionista concibe como el antisemitismo que padecía la judería de Irak haciendo un paralelismo entre este suceso y los pogromos sufridos por los judíos en Europa, Salima narra este hecho como excepcional, único, no como el corolario de una política de antisemitismo institucionalizado, ni tampoco como característico de las relaciones cotidianas entre los árabes

\footnotetext{
${ }^{17}$ Se refiere al heredero del trono. El rey Ghzi I murió en un accidente de tránsito en 1939, su hijo y heredero del trono, Faisal II, tenía sólo cuatro años; entonces el primo de Ghzi I, Emir Abdul-Illah, fue designado en su lugar.
} 
musulmanes y sus vecinos judíos. Ella relaciona el acontecimiento con procesos políticos mundiales, por un lado la influencia nazi sobre Irak, por otro lado con la demora de la entrada de las fuerzas británicas a Bagdad. La postura de Salima rechaza al argumento sionista que sostiene que el odio a los judíos es una característica arraigada en los árabes y que marca sus relaciones con los judíos.

Más aún, en su testimonio ella desarticula el colectivo judío y el colectivo árabe, que en la narrativa sionista aparecen como entes adversos, en tanto los árabes se presentan como los enemigos absolutos del movimiento sionista. Los judíos no eran un macizo y en general se dividen en dos clases: ricos y pobres que vivían en barrios separados. Los testimonios enseñan que el Farhud sólo afectó a los judíos que vivían en barrios pobres. Los atacantes se abstuvieron de entrar en los barrios ri$\cos ^{18}$ Tampoco el colectivo árabe era uniforme: había beduinos que saquearon, nacionalistas pronazis que asesinaron, junto con vecinos pobres que les dieron protección a ella y a su hermana, y el ejército jordano, que con su entrada en la ciudad detuvo las persecuciones. Ella misma se disfrazó de muchacha árabe, y fue a ver los disturbios. La posibilidad de imitación rompe las categorías binarias de judío/árabe, y como demostraré más adelante, no es la única vez que Salima se disfrazó de árabe, y el Farhud no es el único caso en que su vida y las de sus familiares son salvadas gracias a los árabes.

Según la narrativa sionista el Farhud es un acontecimiento constitutivo a partir del cual en los judíos se despiertan sentimientos nacionales que se hacen realidad en la aliá $^{19}$ a Israel.

${ }^{18}$ Un tema central que surgió en la entrevista fue el de las clases sociales. Salima describe numerosos sucesos cuya explicación y análisis es clasista, en tanto mujer consciente de su posición en la estructura estratificada. Sin embargo, debido a la extensión limitada del presente artículo, no voy a presentar este tema en esta ocasión.

${ }^{19}$ En hebreo la palabra "aliá" (ascenso) que designa a la inmigración a Israel, significa el ascenso de grado moral, de un lugar considerado moralmente degene- 
Sin embargo, según el relato de Salima, no es así: justo después del Farhud comienza una etapa de florecimiento económico. En palabras suyas: "se volvió América". Ella no alude a la idea ni a planes para emigrar de Irak como consecuencia de Farhud, sino justamente a una solidez económica.

Según su relato ella y su familia se ven obligados a dejar Irak y a llegar ${ }^{20}$ a Israel como consecuencia de la declaración de Estado de Israel por el movimiento sionista y la guerra de 1948 que le siguió.

Continúa su narración: "Vivíamos juntos en las buenas y en las malas... Entonces se produjo 'jarb' de Israel (en árabe: guerra de Israel). Guerra de Israel. Nos odiaron, con un odio mortal. Porque... vinieron refugiados".

Contrariamente al ethos sionista según el cual el movimiento sionista y la fundación del Estado de Israel salvaron a los judíos de su vida en el exilio, Salima presenta una postura que sostiene que es justamente el movimiento nacional judío el que condujo a la demolición de las relaciones entre musulmanes y judíos, destruyendo el equilibrio en el tejido formado por las relaciones entre la comunidad judía y sus vecinos árabes musulmanes. Salima rechaza la terminología sionista y junto con ella el halo heroico que envolvió a la guerra de 1948 "guerra de la independencia / guerra de la liberación" (una guerra en la que una minoría judía venció a una mayoría árabe que deseaba exterminarla), y prefiere utilizar la lengua árabe, y denominar a esta guerra como "la guerra de Israel". El apodo "guerra de Israel" da cuenta de distancia, de una guerra que no hizo avanzar

rado a otro que se considera más elevado; un lugar al que es necesario ascender. Por eso en el léxico sionista el concepto habitual es "olé" y no "inmigrante".

${ }^{20}$ Escogí la palabra "llegada" y no los conceptos convenidos de "inmigración" o "aliá" por las connotaciones ideológicas propias de cada uno de dichos conceptos: el léxico sionista usa la palabra "aliá" de los judíos a la tierra de Israel: dicho término alberga la deuda moral del inmigrante por el pretendido ascenso ético que denota. Por otro lado, la escuela postsionista utiliza el término universal "inmigrante" a fin de evitar el sentido particular sionista del concepto "olé". Yo prefiero 
los intereses judíos universales, sino por el contrario, una guerra extraña que afectó profundamente la posibilidad de seguir viviendo como una comunidad judía en un país árabe. El desarrollo de la idea de una nacionalidad judía, el reclamo de un Estado judío en Palestina, y como consecuencia de esto el conflicto con los Estados árabes, son presentados por ella como motivos del odio a los judíos en los países árabes. Irónicamente, el movimiento que se jactaba de salvar a los judíos, es causante de la destrucción de su comunidad. Hoy contamos con una larga de fila de investigadores postsionistas abocados a los temas críticos representados por Salima. ${ }^{21}$

De acuerdo con el ethos sionista, la liberación de los judíos árabes se produjo de una manera casi mágica: los nombres otorgados a los operativos de emigración de los judíos de los países árabes "alas de águilas", "alfombra mágica", nombres tomados del mundo de las leyendas orientales, reflejan la concepción de que los judíos árabes fueron salvados por los osados enviados sionistas que organizaron operativos de rescate y salvación, elevando a los judíos hacia la tierra prometida. El relato de Salima propone una postura crítica tanto a esta historiografía sionista, como al sistema de representaciones y estereotipos establecidos por la conciencia orientalista que subyace a la conciencia sionista.

Según la narración de Salima, ella no fue "salvada" por el movimiento sionista, sino que la salvó su propia sabiduría, su ingenio. De su relato surge la idea de que el nacionalismo judío la expuso al peligro. Y su narración no es la de la liberación debida al sionismo, sino una historia de refugiados. Salima fue obligada a dejar Irak ilegalmente y llegar a Israel. Su recorrido duró casi un año.

hacer uso de la palabra "llegada", que es la palabra utilizada por la entrevistada y que está exenta de connotaciones ideológicas.

${ }^{21}$ Shohat 1988; Swirski 1995; Ben-Dor 1999; Shenhav 2003. 
En 1950 fue promulgada en Irak una Ley de Desnaturalización que permitía por primera vez a los judíos salir de Irak al renunciar a su nacionalidad iraquí. La vigencia de la ley fue limitada a un año y en ese lapso (mayo de 1950-junio de 1951) se fueron de Irak más de cien mil judíos iraquíes que llegaron a Israel la mayoría en aviones directos desde Irak, y una minoría (alrededor de dieciseismil) vía Irán. ${ }^{22}$ En los registros de las instituciones iraquíes mi abuela figuraba como persa $^{23}$ y no como ciudadana iraquí ${ }^{24}$ y por esta razón no pudo dejar Irak con la Ley de Desnaturalización. Narra:

Hubo taskit al jancia (en árabe: desprendimiento de la nacionalidad), es una lista de los que botan (renuncian a) su documento de identidad. Yo tenía una hija de un mes, Tzila. Entonces dije: "¿Qué es esto? Seguramente nos engañan”. Dijeron: "Vamos a Israel". El gobierno escribió en los diarios, el que quiere irse se irá, no hay que temer. Entonces fuimos. Nos inscribimos. Pero en mi documento de identidad figuro como persa. A los persas no les permitían irse, los enviaban a Persia. De Persia se iban a Israel. Era difícil, querían separarnos, que yo me fuera con mis padres a Persia y mi marido con las niñas, de Irak a Israel. De repente su familia nos envía un telegrama: 'Vengan a Basrah $^{25}$ y nosotros pasaremos a recogerlos allá'. Nos levantamos y fuimos a Basrah, yo tenía a tu madre de cuatro años y Tzila de un mes. Tenía otra hija más grande,

22 Véase Shenhav 2003.

${ }^{23}$ Persia es hoy Irán. Limita con Irak en el este y en el sur; "Shatt al Arab", el afluente común al Éufrates y al Tigris, marca la línea divisoria entre Irán e Irak.

${ }^{24}$ En 1934 el servicio militar en Irak se volvió obligatorio para los ciudadanos. Para evitar que su único hijo se enrolase en el ejército iraquí, el padre de mi abuela sobornó a un funcionario del ministerio del interior iraquí que se ocupó de que en su documento de identidad figurara como inmigrante persa y no como ciudadano iraquí. Sus registros como persa en las instituciones iraquíes, si bien evitaron el reclutamiento del hijo al ejército iraquí, produjeron complicaciones en las posibilidades de salida de ese país.

${ }^{25}$ Basrah es la segunda ciudad (en tamaño e importancia) y en la concentración de judíos. Se ubica en el sur de Irak, en la ribera del "Shatt al Arab". 
Samira, cuyos tíos se la llevaron a la tierra de Israe ${ }^{26}[\ldots]$ Fuimos a Basrah. Lo que logré vender, lo vendí. Después los árabes ya no querían comprar. Dijeron: "De todos modos ustedes nos van a dejar las cosas aquí". Muchos judíos no vendieron sus casas. Entregaron sus llaves y se acabó, vinieron a Israel. Llegamos a Basrah. En Basrah estuvimos casi dos meses, en casa de nuestra familia. Ellos también vendieron todas sus cosas. Dormíamos en el piso, no había sillas ni mesa. Pero la casa no pudieron venderla. Una casa grande, con seis habitaciones. Era verano, dormíamos sin colchones, sin cobijas, sobre el piso. Nos poníamos algo debajo de la cabeza y así dormíamos. Comida era difícil comprar. No teníamos dinero. Entonces vendimos nuestras ropas, todo lo que había vendimos. El oro (las joyas de oro) vendimos. Dos meses después vino una mujer y dijo: "Me envía la familia, me voy a llevar a tu hija". Mi hija (Mazal) tenía más o menos 3-4 años. ¿Cómo voy a entregarle a mi hija a alguien que no conozco? No acepté. Entonces el marido de esta señora fue a $\operatorname{Abadan}^{27}$ y me trajo una carta de la abuela. En ella decía que no tenga miedo, que ellos conocen a esa señora, su marido trabaja con ellos, y que yo mande con ella a la niña. Entonces envié con ella a la niña. Dos días más tarde me mandaron una carta: "Ella está con la abuela, no te preocupes". Les creí. Los caminos estaban cerrados, no se permitía el paso. Sabían que los judíos pasaban por allí. Esperamos. Mientras, la niña llora allá. Esperamos casi dos meses. Llegó Yom Kipur (el día del perdón) y vino uno a decirnos esta noche vendremos a recoger a tu marido y mañana a ti. Mi marido se fue esa noche con ellos. No sé cómo llegó. Pasada la fiesta el señor no vino. Me quedé sola allá casi un mes, la bebita y yo. Después vinieron dos hombres y dijeron: "Esta noche salimos, prepárate". Entonces me puse la abaya,

${ }^{26}$ En este momento, Salima detalla cómo se sucedieron los hechos por los cuales su hija mayor, Samira, de seis años de edad, es llevada por sus tíos y llega con ellos a Israel. Prefiero aquí no dar detalles de esta historia compleja. Sólo quisiera agregar que Samira, con sus apenas seis años, al llegar a Israel fue enviada a un kibutz, y debido a las duras condiciones económicas en las que vivía su familia en Israel, nunca volvió a vivir con ellos.

${ }^{27}$ Abadan: ciudad petrolera situada en la frontera entre Irak e Irán. 
vestimenta árabe, cubrí mi rostro y con una bebita de 6-7 meses en mis brazos. Caminé un día entero. Cruzamos el río de Basrah. De pronto nos agarró uno. Los hombres que me mostraron el camino dijeron que no me conocían. ${ }^{28}$ Entonces me agarró un árabe, de dos metros de altura, y de ancho... así de gordo. Me dijo: "Ven, perra judía, te quieres ir a Israel". Yo lloraba. La niña lloraba.

"Bota a la niña, quítate la abaya". Me quité la abaya.

Me dijo: “¿Qué quieres? ¿Qué haces aquí?”. Lloré. ¿Qué le iba a contar? Le conté una mentira. Le dije que mi marido me abandonó y lo perdí, tomó a otra mujer y me dejó con una hija. Hablé con él en árabe musulmán. "Quiero hacer regresar a mi marido, por eso voy a ver a su familia en Abadan." Me dijo: "No es cierto. Eres una judía que quiere ir a Israel".

Le dije: "Por la vida del profeta Mahoma, no a Israel, voy a Abadan". No me creyó. Entonces le dije: "Soy tu hermana". Me quité la abayah. "Soy tu hermana, haz conmigo lo que quieras." Escuchó. Cuando les dices que eres su hermana te ayudan. Me dijo: "Eres judía". Le dije: "No. Vivo con musulmanes. Estás escuchando que te hablo en musulmán. ¿Cómo ves que soy judía?" "Tienes cara de judía pero tu manera de hablar es como la de los musulmanes”. Le dije: “¿Ves?”. Me dijo: “'Tienes dinero?”. Le dije: "La verdad es que no tengo". Me dijo: “¿Y cómo andas sin dinero?”. No tenía alternativa así que le di el dinero que me quedaba. Le dije: "Les creo". Conozco a los musulmanes, si les dices que estás en sus manos no te harán nada. Me dejó en libertad. Me dijo: "Ve derecho". Le dije: "Mi hija necesita agua". Me dijo: "Ve y bebe del río. De mí no recibirás nada. Muchos judíos pasan por aquí y tratan de engañarnos". Entonces todo se arregló. Volvieron los dos muchachos árabes que tenían que mostrarme el camino pero se equivocaron. Llegó la noche. Me llevaron de regreso al lugar del inicio, a la casa de unos beduinos. La niña estaba enferma. Me llevaron a la niña, le dieron leche, me trajeron

${ }^{28}$ En este punto Salima pasa a hablar en árabe. El texto que aparece aquí fue traducido por mi abuelo, ya que, como lo dije antes, no hablo árabe. 
pan. Nos recibieron. A las cinco de la mañana me dijeron "ya'alla". Nos levantamos y caminamos cuatro horas. Y Tzila tenía 40 grados de fiebre, la pobre. Casi se acaba (muere). Entonces uno de estos árabes me dijo "Bota a la niña aquí. Se muere. Pronto va a morir y vas a estar libre". Le dije: "No voy a tirar a mi niña". Entonces seguimos caminando. Hacía calor y se hizo mediodía. Entonces me llevaron a otra casa de árabes. Me llevaron a la niña, le dieron una medicina, aceite, no sé qué. Yo lloraba. Me dijeron: "No temas. Es nuestra hija. No le haremos nada". La lavaron y la atendieron. Me dijeron que yo descanse hasta el anochecer. ¿Pero cómo dormir? Temía por mi hija. Entonces vino una mujer, me vio y me dijo: "En nuestra casa estás bien". Llegó la noche. Salimos nuevamente. Caminamos una hora y vimos el río. Me dijo el árabe: "Cruza el río, al llegar a la otra orilla ya es Persia. Habla con ellos. Diles que eres una judía que quiere llegar a Israel y te ayudarán”. Ese día el río estaba lleno de agua. ¿Cómo íbamos a cruzar? Bajé al río. Había un metro y medio (de profundidad de las aguas). Pasé al otro lado. Allí dije que soy judía, que venía de Irak. Me condujeron a la sinagoga a donde llevaban a todos los judíos. Mi marido escuchó que llegué y vino a buscarme. Vi a mi hija, a mi marido. De allí nos fuimos a Abadan. Nos quedamos tres meses en Abadan. Después nos llevaron a Teherán ${ }^{29}$ a un campamento transitorio. Era un campamento grande. Todo aquel que quería ascender a Israel estaba allí. Éramos veinte almas en un cuarto. Dormíamos unos arriba de otros. Era muy duro. Estuvimos en ese campamento casi dos meses hasta que nos llegó el turno de ascender [inmigrar] [...]. Cuando llegamos a Israel nos quedamos un mes en un campamento de inmigrantes en Haifa. Nos pusieron en una tienda de campaña. Íbamos mañana, tarde y noche a pedir comida. Pero mi hija estaba enferma. Entonces la llevé a Kupat Jolim [el Seguro Social] en el campamento, le dieron medicinas y se curó. ¿Acaso la iba a tirar allá? Por Dios que hubiese regresado a Irak con tal de no abandonar a mi hija.

29 Teherán, capital de Irán. 
La historia de Salima no es únicamente un relato de refugiados (en contraposición con el ethos de la redención), sino que es una historia de osadía, de coraje, creatividad, actividad y entrega. Una narración que presenta una postura contraria al estereotipo creado por la ideología sionista orientalista, que describe a las mujeres judías árabes como meros objetos pasivos, y les atribuyen cualidades de pasividad, incapacidad de adaptación, incultas y egocéntricas, con un egocentrismo que les imposibilita ocuparse de sus hijos. En la literatura de investigación las judías árabes "típicas" fueron diagnosticadas bajo el padecimiento de una crisis que se explica por el paso de una sociedad tradicional a una sociedad moderna. El supuesto que se encuentra en la base de ese trabajo es que la vida en un Estado moderno mejora para la mujer oriental, y tanto su posición como sus condiciones mejoraron respecto a su vida en la sociedad árabe. Este discurso fue fortalecido no sólo en la investigación académica que trató las etnias en Israel, sino que también fue reforzado por el discurso feminista que hizo un paralelismo entre lo occidental y el progreso por un lado, y entre lo oriental y el primitivismo como su contraparte. El discurso mayoritario en Israel propone que la situación de las mujeres judías árabes mejoró con su llegada al Estado moderno, y que deben estar agradecidas con el movimiento sionista que hizo posible el ascenso de su estatus. Cuando se escuchan historias personales se puede ver que a pesar de que en muchos aspectos de la vida de las mujeres hubo mejoras (por ejemplo en cuanto a su adquisición de conocimientos), en otros aspectos ha empeorado. Motzafi-Haller sostuvo que la llegada a Israel se encontró envuelta en el pasaje de una vida familiar en el sentido amplio a una vida de familia nuclear, un pasaje que reduce de manera significativa la red de apoyo que se encontraba a disposición de la mujer en caso de necesitarlo. De este modo, mujeres que en tiempos difíciles podían apoyarse en sus familiares cercanos, en la sociedad moderna dependen de la ayuda 
de factores institucionales que muchas veces no pueden apoyar a la mujer en lo que necesita (por ejemplo cuando se trata de una mujer golpeada). En las palabras que siguen de Salima, hay un testimonio tanto de la capacidad para actuar y la actividad de las mujeres orientales, como también del empeoramiento de la situación de estas mismas mujeres judías árabes en Israel:

Después del campo de inmigración [ascenso, aliá] nos enviaron a Beer Sheva. ${ }^{30}$ Era invierno, llovía, la carpa se nos cayó encima, y yo con dos bebitas... Una semana más tarde nos dieron una barraca porque tengo dos hijas pequeñas. La barraca era de tres metros por tres metros. Recibíamos comida por medio de tarjetas, mensualmente. ${ }^{31}$ Nos formábamos en una fila hasta recibir la ración. No había comida. Era duro, difícil [...] cuando una estaba embarazada solían darle cinco metros de tela, para coserle ropa al niño, envolverlo, nos alcanzaba con eso. Y yo, mi parto de Rivka, fue en casa. Y el resto de los niños en el hospital. A Rivka la traje [al mundo] en casa. Hicimos una huelga por la causa de la enfermera. Había una partera iraquí que querían quitar del hospital. Y nosotras la queríamos, la conocemos de Irak. Ella asistió mis partos en un hospital de Irak, en los nacimientos de Samira y de Tzila. Era partera desde que tenía veinte años y todos en Irak la querían. Aquí querían quitarla, entonces hicimos una huelga —no volveremos al hospital hasta que la regresen a su trabajo en el hospital-. De verdad varias tuvieron sus partos en las casas hasta que la reintegraron. Y yo di a luz a Rivka en casa.

Ahora bien, justamente en el Estado "moderno", "avanzado", Salima da a luz en su domicilio, mientras que en el país oriental, "subdesarrollado", Salima dio a luz en el hospital. La huelga de Salima y de las otras mujeres no se reduce a la constatación

\footnotetext{
${ }^{30}$ BeerSheva: población desértica, alejada del centro cultural y económico, situada en el sur de Israel.

${ }^{31}$ Entre 1949 y 1952, por causa de la difícil situación económica en que se encontró el joven Estado, se decretó en Israel un régimen de austeridad por el que se adjudicaban raciones de comida adecuadas al tamaño de las familias.
} 
y demostración de la existencia de un sujeto agente en una narrativa que hace caso omiso de su existencia, sino que revierte el ethos sionista del progreso y la ilustración. Sólo por medio de narrativas personales ${ }^{32}$ es posible romper las dicotomías OrienteOccidente, moderno-primitivo, desarrollado-subdesarrollado, y así ver cómo funcionan distintos sistemas de fuerzas de maneras diferentes, en diversos grupos de mujeres, y cómo van estructurando la existencia de estas mujeres.

La historia de Salima negocia con la narrativa hegemónica desde una postura crítica. Salima da forma a un relato femeninooriental que desafía las categorías del pensamiento hegemónico respecto a las "mujeres orientales".

Una escritura narrativa personal es una práctica de resistencia frente a la violencia epistemológica constitutiva de la historiografía sionista. El punto de vista de mujeres judeo-árabes inmigrantes hace penetrar en el metadiscurso enfocado a la experiencia masculina-judía no sólo la experiencia de las mujeres, sino también el sesgo étnico y de clase, ausente en el debate histórico en Israel, que tendió a ignorar temas orientales. ${ }^{33}$ Una "historia desde abajo", a través de relatos personales locales, puede proponer una historia alternativa y desafiar al discurso hegemónico, que a su imagen formó identidades sometidas.

El desnudamiento de una historia alternativa permite analizar el proceso de exclusión de mujeres judeo-árabes inmigrantes de los recursos culturales y materiales, y cuestionar las jerarquías sociales para rechazar su legitimidad.

\section{Epílogo}

En la sociedad israelí la lengua árabe es considerada como lengua del enemigo árabe. Los hijos de Salima, que interiorizaron

\footnotetext{
${ }^{32}$ No encontré testimonio del relato de la rebelión de las mujeres en la historia documentada, sino solamente en las conversaciones con otras mujeres.

${ }^{33}$ Motzafi-Haller 2005, 268.
} 
el discurso sionista, y como tantos orientales, intentaron sacudirse todo signo que los hiciera identificables con el enemigo árabe, no aceptaron que ella hablara en árabe, y le exigieron aprender hebreo. Mi madre jamás estuvo de acuerdo en que mi abuela me hablase en árabe. Ella sostiene que no sabe hablar en esa lengua. Mi madre, que llegó de Irak a Israel a los cuatro años de edad, borró la lengua de su madre y con ella borró su propio pasado, y adoptó la lengua, la cultura y la conciencia orientalista del Estado sionista-israelí. Hace varios años que de vez en cuando "viajo en el tiempo" hacia las comarcas del olvido, hacia el relato de mi abuela, en un intento de "pasar por la historia el cepillo a contrapelo" con el objeto de volver a escribir la historia de mujeres judeo-árabes en Israel. La escritura histórica resultante de la experiencia de las mujeres judeo-árabes no es sólo importante porque visibiliza la experiencia histórica de sujetos que no entraron en la narrativa histórica israelí, sino sobre todo porque pone en evidencia limitaciones en el discurso historiográfico existente y abre la puerta a un análisis histórico social feminista alternativo.

\section{REFERENCIAS}

Ben Dor, Tzvi [en hebreo], 1999.“La maravillosa historia de los orientales”, en Perlson Inbal (coord.), La revolución oriental, Jerusalén, Centro de Información Alternativa.

GaL, Meir [en hebreo], 1997. "Nueve entre cuatrocientos (los orientales según Kirschenboim)", en la exposición Kadima: el Oriente en el arte de Israel, Tel Aviv.

HaRdings, Sandra, 1998. Is Science Multi-Cultural? Postcolonialism, Feminism, And Epistemologies, Bloomington e Indianapolis, Indiana University Press.

Motzafi-Haller, Pnina, 2001. "Scholarship, Identity and Power: Mizrahi Women in Israel", Signs: Journal of Women in Culture and Society, 26:3, 697-734. 
Motzafi-Haller, Pnina [en hebreo], 2005.“Una ashkenaziah en cautiverio: lineamientos para una historiografía crítica feminista en Israel", en Tova Cohen y Shaul Regev (eds.), Mujer en el este, mujer del este, Ramat-Gan, Israel, Bar-Ilan University.

SAID, Edward, 1978. Orientalism, New York, Pantheon.

Shenhav, Yehuda [en hebreo], 2003. Los judíos árabes: nacionalidad, religión y etnia, Tel Aviv, Am Oved Publishers.

Sнонат, Ella, 1988. "Sephardim In Israel: Zionism from the Standpoint of its Jewish Victims", Social Text, 19-20, 1-35.

SMith, Sidonie, 1993. "Who's Talking/Who's Talking back? The Subject of Personal Narrative", Signs, 18:2, 392-407.

Somekн, Sasson [en hebreo], 2004. Bagdad ayer, Tel Aviv, Hakibutz Hameujad.

Stivers, Camilla, 1993. "Reflection on Role of Personal Narratives in Social Science", Signs, 18:2, 408-426.

Swirski, Shlomo [en hebreo], 1995. Semillas de desigualdad, Tel Aviv, Breirot.

Wisweswaran, Kamala, 1994. Fictions of Feminist Ethnography, Minneapolis y London, University of Minnesota Press.

Yapp, M. E., 1996. The Near East since the First World War. A History to 1995, London, Addison Wesley Longman. 